\title{
The Hornless Australian Burrowing Mayfly Ulmerophlebia (Ephemeroptera: Leptophlebiidae)
}

\author{
Yeon Jae Bae ${ }^{1, *}$, Kyla J. Finlay², Ian C. Campbell ${ }^{3}$ \\ ${ }^{1}$ Division of Life Sciences, College of Life Sciences and Biotechnology, Korea University, Seoul 136-701, Korea \\ ${ }^{2}$ Biosciences Research Division, Department of Primary Industries, Bundoora, VIC 3083, Australia \\ ${ }^{3}$ School of Biological Sciences, Monash University, Melbourne, VIC 3800, Australia
}

\begin{abstract}
The hornless Australian burrowing mayfly genus Ulmerophlebia Demoulin (Leptophlebiidae) is revised based on comprehensive examinations of adult and larval material collected throughout Australia. Two new species [Ulmerophlebia deani n. sp. and U. minuta n. sp.] and three named species [U. annulata (Harker), U. mjobergi (Ulmer) and $U$. pipinna Suter] are included. The larva of $U$. deani can be distinguished by the moderately developed apicomedial expansion of gills and W-shaped markings on the abdominal terga. The male adult of $U$. minuta can be easily distinguished by the greatly reduced penes. Descriptions, diagnoses, line-drawings of key characters, material and distributional data, taxonomic remarks and adult and larval keys are provided.
\end{abstract}

Keywords: Ulmerophlebia deani n. sp., Ulmerophlebia minuta n. sp., Leptophlebiidae, Ephemeroptera, description, Australia

\section{INTRODUCTION}

Larvae of the hornless Australian burrowing mayfly genus Ulmerophlebia Demoulin (Leptophlebiidae) are adapted to burrow in beds of streams and rivers. Although they lack obvious burrowing devices such as 'cephalic tusks' or 'horns' present in the horned Australian burrowing mayfly genus Jappa Harker (Campbell, 1990; Bae et al., 2004), their flattened and enlarged 'shovel-like' clypeal development probably aids them in fossorial behavior (Bae et al., 2004).

Demoulin (1955) established the genus Ulmerophlebia with Euphyurus mjobergi Ulmer as the type species. Suter (1986) described the larval stage of the genus for the first time when he described an additional species of Ulmerophlebia, $U$. pipinna Suter. The genus was also discussed by Riek (1970), Peters and Campbell (1991) and Dean and Suter (1996). Dean (1999) gave larval diagnoses of Ulmerophlebia species when he provided larval keys to two named and additional three unnamed species of Ulmerophlebia. Bae et al. (2004) refined the generic concept of Ulmerophlebia together with its sister genus Jappa Harker, 1954. The monophyletic relationships of the Jappa-Ulmerophlebia clade in the Australian Leptophlebiidae were well supported by Bae et al. (2004), Christidis (2005) and Finlay and Bae (2008).

The purpose of this study is to revise members of the genus Ulmerophlebia with descriptions and redescriptions of the known life stages of existing species including two new species.

\section{MATERIALS AND METHODS}

Type and voucher specimens and additional fresh material of Ulmerophlebia housed predominantly in the Museum of Victoria (MV), the Australian National Collection in Canberra (ANIC) and Monash University (MU) were examined for this study.

In the descriptions, eye size is measured by the ratio (B/D) of the shortest distance between compound eyes to the longest dorsal diameter of a compound eye. Gill expansion rate is defined by the ratio of the vertical height of apicomedial expansion of gill lobe (measured by the direct line of the height from the base of apical filament of gill to the apex of expansion) against gill lobe length from the base of gill to the base of apical filament of gill. Other terminology, measurement and general methods follow those of Bae and McCaf- (c) This is an Open Access article distributed under the terms of the Creative Commons Attribution Non-Commercial License (http://creativecommons.org/ licenses/by-nc/3.0/) which permits unrestricted non-commercial use, distribution, and reproduction in any medium, provided the original work is properly cited.

pISSN 2234-6953 eISSN 2234-8190
*To whom correspondence should be addressed

Tel: 82-2-3290-3408, Fax: 82-2-3290-3963

E-mail: yjbae@korea.ac.kr 
ferty (1991), Dean (1999), and Bae et al. (2004). Abbreviations used in this study follow those of Bae et al. (2004): male imago (MI), female imago (FI), male subimago (MS), female subimago (FS), larva (L) and egg (E); New South Wales (NSW), Queensland (QLD), Victoria (VIC) and South Australia (SA).

\section{SYSTEMATIC ACCOUNTS}

\author{
Order Ephemeroptera \\ Family Leptophlebiidae \\ Genus Ulmerophlebia Demoulin, 1955
}

Ulmerophlebia Demoulin, 1955: 228 [MI, FI]; Suter, 1986: 352 [MI, L]; Dean \& Suter, 1996: 44 [L]; Dean, 1999: 74 [L]; Bae et al., 2004: 6 [MI, FI, L, E].

Type species. Ulmerophlebia mjobergi (Ulmer), 1916. Redescription. Imago: Male body length $6.9-8.7 \mathrm{~mm}$, caudal filaments $7.5-11.0 \mathrm{~mm}$; female body length $6.3-8.6 \mathrm{~mm}$, caudal filaments $10.6-10.7 \mathrm{~mm}$. General body colour light yellow with dark purplish brown markings. Male compound eyes dorsally oval and dome-shaped, with anterior margin circular and posterior margin slightly attenuating from lateral view ('bicycle helmet-shaped'), contiguous $(\mathrm{B} / \mathrm{D}=0-0.06)$; basal compound eyes anteroventrally pronounced. Female compound eyes widely separated $(\mathrm{B} / \mathrm{D}=3.11-4.91)$. Forewings transparent, often with dark purplish brown markings in basal, central and apical areas, length 6.6-8.5 mm, width 2.2-3.2 mm; longitudinal veins light brown to dark purplish brown; crossveins light brown to dark purplish brown (basally and anteriorly located crossveins often darker and more heavily infuscated); crossveins C-Sc $12-19$; $\mathrm{MP}_{2}$ basally connected to $\mathrm{MP}_{1}$ and $\mathrm{CuA} ; \mathrm{ICu}_{1}$ basally connected to $\mathrm{CuA}$ and $\mathrm{CuP}$ (angle between $\mathrm{ICu}_{1}$ and crossvein $\mathrm{ICu}_{1}-\mathrm{CuP}$ larger than angle between $\mathrm{ICu}_{1}$ and crossvein $\mathrm{ICu}_{1}-\mathrm{CuA}$ ); stigmatic area not anastomosed. Hindwings transparent, length 1.3-1.9 mm, width 0.7-1.0 mm; crossveins C-Sc 4-10, concentrated apically; costal margin round with weakly developed costal projection at $1 / 3$ basally to midlength. Male foretarsi $>$ foretibiae $>$ forefemora; foretarsal segment $2 \geq 3>4>5>1$. Female foretibiae $>$ forefemora $>$ foretarsi. Claws dissimilar. Penes Y-shaped or V-shaped, normally developed or rudimentary; forceps 3-segmented; forceps basal segment parallel-sided, narrowing at 1/2-2/3 length; forcep segments 2 and 3 often indistinctly demarcated. Caudal filaments light yellow, often with purplish brown to dark brown stripes and annulations at joints.

Larva: Male body length 6.2-9.8 mm; caudal filaments 5.5 $-10.0 \mathrm{~mm}$. Female body length $6.8-11.2 \mathrm{~mm}$; caudal fila- ments 5.5-13.2 mm. Body surface glassy and relatively less setose. General body colour light yellow to light brown with dark purplish brown markings. Head without cephalic tusks. Clypeus greatly developed (length $0.38-0.45 \mathrm{~mm}$ ), with pronounced sublateral tubercles, with fields of hair-like setae subapicolaterally and subbasolaterally. Antennae with whorls of hair-like setae at each segment. Labrum slightly narrower than clypeus, slightly wider distally; dorsal surface with basal and subapical hair-like setal fringes; subapical setal fringe laterally longer and not densely arranged; anterior and lateral margins with dense hair-like setal row; anterior margin slightly concave, with prominent median tubercle, with three pairs of rudimentary submedian denticles; ventral surface with dense hair-like setal field along anterior margin, with row of 15-18 stout setae on subanterior margins, with paired fields of 10-15 hair-like setae on central areas opposite to median line. Mandible dorsolateral margins with very long hair-like setal row; ventral surface without setal row; inner incisors slightly smaller to as large as outer incisors; incisors with 2 -3 apical teeth and 0-4 lateral denticles; prostheca rudimentary, with well developed fringe. Hypopharynx superlinguae laterally curved and pointed apically. Maxillae with dense hair-like setal field, mixed with row of comb-like setae almost entirely on galealacinial crown, without medioapical comblike seta, with row of dense hair-like setae on medial margin; maxillary palp 3-segmented; segment 3 indistinctly demarcated from segment 2 , with moderately developed setal field along outer margin. Labial glossae dorsoventrally elongated and ventrally stalked, with dense hair-like setae; paraglossae with dense hair-like setal field dorsoapically; labial palp 3segmented; segment 3 indistinctly demarcated from segment 2, pointed apically, with dense hair-like setal field along outer margin, with stout setal row along inner margin. Pronotum anterolateral margins round; lateral margins with row of hair-like setae. Forefemora $\geq$ foretibiae $>$ foretarsi $>$ foreclaws; forefemora with a few hair-like setae on dorsal and ventral surfaces, with hair-like setal field along posterior margin (anterior margin with few hair-like setae); foretibiae with relatively sparse hair-like setae (filtering setae) dorsally and along outer margin (inner margin with few hair-like setae), with stout setal field (raking setae) ca. 5/6 apically on inner margin; foreclaws with row of tiny teeth basally. Abdominal terga light yellow to light brown, mostly with broad submedian dark brown stripes, with or without long hair-like setal field along median line, with hair-like setal row along lateral margins; abdominal segment VI-IX with moderately to well developed posterolateral projections. Abdominal sterna bare. Gills on abdominal segment I-VII, double; both lamellae with indistinct to distinct tracheae, with single apical filament, clothed with fine marginal seta, with weakly to strongly developed apicomedial expansion. Caudal filament with whorls 
of setae.

Egg: Egg oval; long axis ca. $1.5 \times$ length of short axis. Colour light yellow in nature, white in alcohol. Egg surface with knob-terminated coiled threads nearly evenly distributed throughout egg surface, with numerous tiny granules throughout egg surface. Polar caps absent.

Diagnosis. Although no fundamental adult key characters are found to distinguish Ulmerophlebia from its sister genus Jappa, the adults of Ulmerophlebia possess smaller number of C-Sc crossveins (12-19) in the forewings and apically concentrated $\mathrm{C}-\mathrm{Sc}$ crossveins in the hindwings, while those of Jappa possess larger number of C-Sc crossveins (20-30) in the forewings and more or less evenly distributed C-Sc crossveins in the hindwings. The larvae of Ulmerophlebia can be easily distinguished from those of Jappa by the lack of the cephalic tusks. The body size of Ulmerophlebia (adult $6.3-8.7 \mathrm{~mm}$, larva $6.2-11.2 \mathrm{~mm}$ ) is generally smaller than that of Jappa (adult 9.4-16.5 mm, larva 10.4-23.8 mm) in both of the adults and larvae. The larvae of Ulmerophlebia can be distinguished from other leptophlebiid genera by the following combination of characters: presence of prominent median tubercle on anterior labrum, absence of cephalic tusks and presence of a somewhat enlarged clypeal margin with sublateral tubercles and subapicolateral and subbasolateral hair-like setal fields.

Distribution. QLD, NSW, VIC and SA.

Remarks. Dean (1999) considered a possible inclusion of Deleatidium annulatum Harker, 1950 and Atopopus spadix Harker, 1950 in Ulmerophlebia, but Bae et al. (2004) did not accept this conclusion based on the original descriptions of the species. However, we herein reevaluate the species Ulmerophlebia annulata (Harker) (see remarks under $U$. annulata).

The suggested common name of this genus is the 'hornless Australian burrowing mayflies'.

Ulmerophlebia annulata (Harker) (Figs. 1A, 2A, 3A)

Deleatidium annulatum Harker, 1950: 19 (MI, F) [holotype stage: MI; locality: Serpentine R., Point Lookout, NSW; deposition: Australian Museum in Sydney (missing)]; Harker, 1954: 255 (L).

Ulmerophlebia AV2: Dean, 1999: 75 (L key).

Material examined. NSW: 3 MI, Jindabyne, 21, 22 Feb 1969, Neboiss A [MV]; 6 FI, Wallagaraugh R at Princess Hwy Br, 29 Jan 1975, Neboiss A [MV]; 3 L, Genoa R at Cann Valley Hwy, 15 Nov 1994, Dean J [MV]; 8 L, Upper Kangaroo R, 28 Oct 1972, Dean J [MV]. VIC: 2 MI, Traralgon Ck, Koornalla, 26 Feb 1974 [MV]; 1 MI, Tennyson Ck at 5 km NW of Buldah, $149^{\circ} 07^{\prime} \mathrm{E}, 37^{\circ} 14^{\prime} \mathrm{S}, 1-7$ Jan 1982 [MV]; 3 MI, Genoa Ck Falls, 3 km W of Genoa, 28 Mar 1974, Ne- boiss A [MV]; 1 MI, Clunes, 6 Jan 1956, Neboiss A [MV]; $1 \mathrm{MI}$, Coliban R at $6 \mathrm{~km} \mathrm{SW}$ of Kyneton, 18 Feb 1973, Neboiss A [MV]; 1 FI, Bells Clearing, $6 \mathrm{~km} \mathrm{~S}$ of Aberielby, 10 Feb 1977, Calder AA [MV]; 4 FI, Mitchell R, 26, 29 Apr 1975, at light [MV]; 1 FI, Diamond Ck at $7 \mathrm{~km} \mathrm{SE}$ of Gembrook, 31 Jan 1976, Wells A, Neboiss A [MV]; 1 FI, North Noorinbee, 20 Mar 1977, Neboiss A [MV]; 1 MI, Upper Gellibrand R, Stevensons Falls, 20 Jan 1982, Neboiss A, Wells A [MV]; 2 MI, 2 FI, 1 MS, Gellibrand R at Bryant Ck Jct, 24, 26 Jan 1982, Neboiss A [MV]; 1 MI, 2 FI, Gellibrand R at Alpine Ck Jct, 28 Jan 1982, Neboiss A [MV]; 1 FI, Healesville, Koranderrk Reserve, 21 Jan 1976, at light, Rankin, Smith [MV]; 8 FI, Yarra R below Upper Yarra Dam, 28 Feb 1976, Neboiss A [MV]; 7 L, Yarra R at Reefton Rd, 17 Feb 1978, Dean J [MV]; 7 L, Yarra R at Hazlewood Rd, 17 Feb 1978, Dean J [MV]; 1 MI, 2 FI, 1 FS, Tonghi Ck, 10 km SW of Cann R, $149^{\circ} 06^{\prime} \mathrm{E}, 37^{\circ} 37^{\prime} \mathrm{S}$, 4 Feb 1987, at MV-light, Walker, McPhee [MV]; 2 MI, 1 FI, Cann R, $33 \mathrm{~km} \mathrm{~N}$ of Cann $\mathrm{R}, 149^{\circ} 11^{\prime} \mathrm{E}, 37^{\circ} 25^{\prime} \mathrm{S}, 5$ Feb 1987, at MV-light, Walker, McPhee [MV]; 1 MI, 1 FI, Cann R, 14 Feb 1999, Finlay KJ [MU]; 1 FI (reared, with L exuvium), 1 FS (reared, with L exuvium), 10 L, 3 Mile Dam, 1 Dec 1997, Finlay KJ [MU]; 1 MI, Jackson Ck, 26 Oct 1997, Finlay KJ [MU]; 1 FI (reared, with L exuvium), Gulf stream, 16 Jan 1999, Finlay KJ [MU]; 1 FI (reared, with L exuvium), Smepthel Ck, 2 Mar 1997 , Finlay KJ [MU]; 1 L(EPH-1845: ANVC), Loddon R at Glenluce-Malmsburg Rd, 22 Nov 1981, Dean J [MV]; 1 L (EPH1816: VVC), same data as EPH-1845 [MV]; 5 L, Rose R, 17 Mar 1999, Finlay KJ [MU]; 1 L, Lake Lilla, 29 Dec 1996, Finlay KJ [MU]; 1 L, Franklin, 11 Feb 1999, Finlay KJ [MU]; 1 L, Morwell, 4 Mar 1999, Finlay KJ [MU]; 3 MI (reared, with larval exuviae), $1 \mathrm{FI}$ (reared, with larval exuvium), $6 \mathrm{~L}$, Licola, Wellington $\mathrm{R}$ at $3 \mathrm{~km} \mathrm{u} / \mathrm{s}$ from Alpine NP entrance, 18 Mar 2001 (emerged 5 Jun 2001 at $18^{\circ} \mathrm{C}$ ), Bae YJ, Govedich F, Bain B [MV, MU]; 1 L, Licola, Wellington R at $3 \mathrm{~km}$ $\mathrm{u}$ /s from Alpine NP entrance, 16 Apr 2001, Bae YJ, Lim KJ [MU].

Redescription. Male imago: Body length $7.2 \mathrm{~mm}$. General body colour light yellow with dark purplish brown markings. Dorsal compound eyes dark orange in alcohol, length 0.92 $\mathrm{mm}$, width $0.81 \mathrm{~mm}$, height $0.44 \mathrm{~mm}$, widely separated anteriorly and meeting posteriorly $(\mathrm{B} / \mathrm{D}=0)$; basal compound eyes dark grey, length $0.59 \mathrm{~mm}$, height $0.33 \mathrm{~mm}$. Antennae 0.75 mm, white; segment 2 dark purplish brown. Thorax colour golden yellow with irregular dark brown markings; pronotum posteromedially greatly concave, medially and posteromarginally black, submedially brown, laterally white; mesonotum golden yellow, posterolaterally light brown with dark brown posteromedian hump; pleura and sterna with various irregular dark brown markings and spots; metanotum dark brown. Forewings hyaline, length $7.9 \mathrm{~mm}$, width $2.6 \mathrm{~mm}$; 

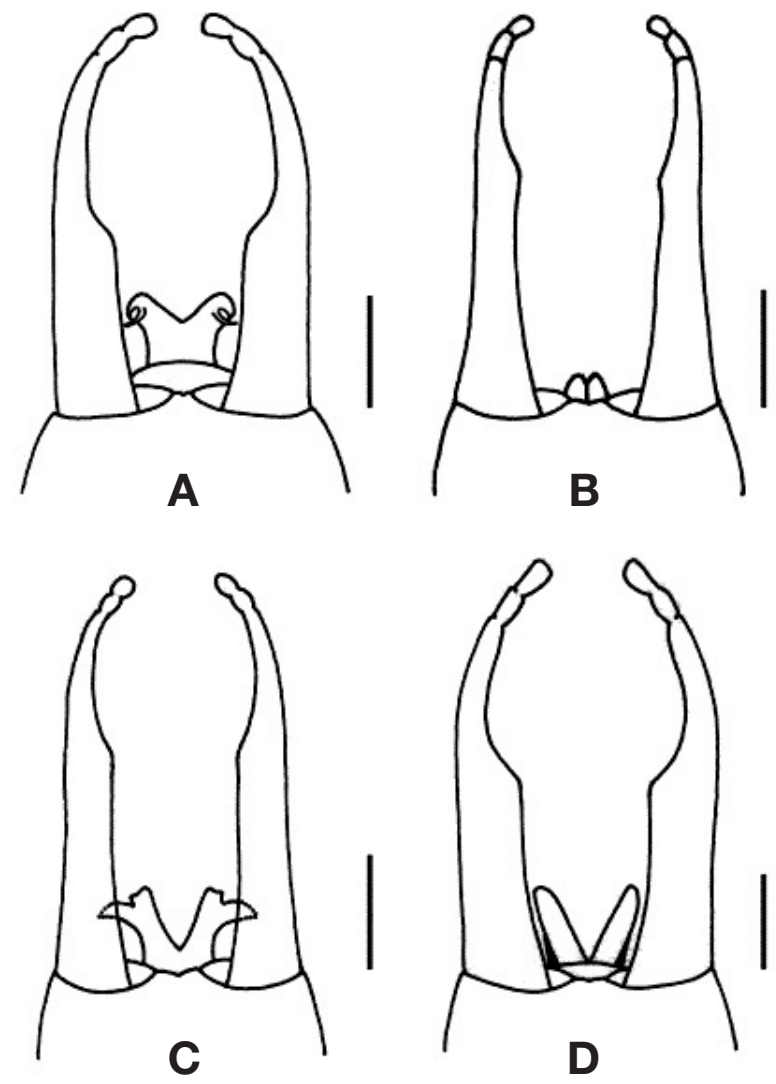

Fig. 1. Male imago genitalia: A, Ulmerophlebia annulata; $B, U$. minuta; C, U. mjobergi; $D$, U. pipinna. Scale bars: $A-D=0.2$ $\mathrm{mm}$.

longitudinal veins stained light brownish; crossveins brown to dark purplish brown and basally and anteriorly thicker in colour; crossveins C-Sc 19, infuscated; crossveins Sc- $\mathrm{R}_{1} 16$, basal $1 / 2$ infuscated; crossveins $R_{1}-R_{2} 14$, slightly infuscated; stigmatic area milky. Hindwings hyaline, length $1.5 \mathrm{~mm}$, width $1.0 \mathrm{~mm}$; longitudinal veins and crossveins (except crossveins C-Sc and Sc- $\mathrm{R}_{1}$ ) hyaline; crossveins C-Sc 6, dark purplish brown, apically concentrated; crossveins $\mathrm{Sc}_{-} \mathrm{R}_{1} 5$, dark purplish brown; costal area round with indistinct costal projection at $1 / 3$ basally; Rs $0.33 \mathrm{~mm} ; \mathrm{R}_{1} 0.70 \mathrm{~mm}$; MPs 0.20 $\mathrm{mm} ; \mathrm{MP}_{1} 0.88 \mathrm{~mm}$. Legs light yellow with joints dark brown; dorsal and ventral forefemora with purplish brown markings basally, at mid-length and apically; forefemora $1.45 \mathrm{~mm}$, foretibiae $2.50 \mathrm{~mm}$, foretalsal segment $10.10 \mathrm{~mm}$, segment $20.68 \mathrm{~mm}$, segment $30.70 \mathrm{~mm}$, segment $40.55 \mathrm{~mm}$, segment $50.25 \mathrm{~mm}$ and foreclaws $0.15 \mathrm{~mm}$; claws dark purplish brown. Midlegs and hindlegs colour and markings similar to forelegs. Abdominal terga dark purplish brown (terga VII-X purplish brown) with broad longitudinal median white stripe (each segment including anteromedian dark spot) and anterosublateral and lateral white areas, with anterolateral dark purplish brown spots as seen in larval abdomen. Sterna with dark purplish brown longitudinal stripe (stripe in each segment posteriorly somewhat broader). Penes (Fig. 1A) white, length $0.13 \mathrm{~mm}$, Y-shaped, with apicolateral dark brown spines (spines ventrolaterally curved); forceps light brown, dark brown apicolaterally, white apicomedially; forceps segment $10.63 \mathrm{~mm}$, segment $20.09 \mathrm{~mm}$ and segment 30.08 $\mathrm{mm}$; forceps segment 1 broad basally and slender apically, with distinct constriction at midlength, arched dorsally at constriction; segments 2 and 3 fused. Caudal filaments light yellow, with dark and light brown alternating joints; cerci $8.8 \mathrm{~mm}$; terminal filament $11.0 \mathrm{~mm}$.

Female imago: Body length $7.3 \mathrm{~mm}$. General body colour and markings similar to male. Compound eyes width 0.28 $\mathrm{mm}$; distance between compound eyes $0.88 \mathrm{~mm}(\mathrm{~B} / \mathrm{D}=3.11)$. Forewings length $8.5 \mathrm{~mm}$, width $2.7 \mathrm{~mm}$; veins somewhat darker in colour than veins in male; venation similar to male. Hindwings length $1.5 \mathrm{~mm}$, width $0.9 \mathrm{~mm}$; veins somewhat stained light brownish; venation similar to male. Abdomen colour and markings similar to male. Caudal filaments similar to male; cerci $9.0 \mathrm{~mm}$; terminal filament $10.7 \mathrm{~mm}$.

Larva: Male body length $6.2 \mathrm{~mm}$; caudal filaments $5.5 \mathrm{~mm}$. Female body length 6.8-7.2 mm; caudal filaments 5.5-6.0 $\mathrm{mm}$. Dorsal body colour light brown to brown with light yellow markings; ventral body and legs light yellow with brown to dark brown markings. Head light brown, length $1.10 \mathrm{~mm}$ and width $1.45 \mathrm{~mm}$, with white areas between lateral ocelli and compound eyes. Male compound eyes width $0.50 \mathrm{~mm}$; distance between compound eyes $0.55 \mathrm{~mm}(\mathrm{~B} / \mathrm{D}=1.10)$. Female compound eyes width $0.20 \mathrm{~mm}$; distance between compound eyes $1.10 \mathrm{~mm}(\mathrm{~B} / \mathrm{D}=5.50)$. Antennae white, length $3.3 \mathrm{~mm}$; segment 2 light brown. Clypeus length $0.38 \mathrm{~mm}$, basal width $0.69 \mathrm{~mm}$, apical width $0.66 \mathrm{~mm}$, with well developed sublateral projections, with ca. 8-10 hair-like setae subapicolaterally, with ca. 10-15 hair-like setae subbasolaterelly. Pronotum length $0.50 \mathrm{~mm}$, width $1.50 \mathrm{~mm}$, with median dark brown stripe; lateral margins white. Mesonotum laterally with dark brown irregular markings; forewingpads with small black spots basally, centrally and laterally. Pleura and sterna with various dark brown markings. Forefemora $1.15 \mathrm{~mm}$, foretibiae $1.00 \mathrm{~mm}$, foretarsi $0.43 \mathrm{~mm}$ and foreclaws $0.15 \mathrm{~mm}$; coxae dorsally with hair-like setal field; trochanters anterodorsally with row of 5-10 hair-like setae. Abdominal terga with broad median light area and anterosublateral light areas with submedian dark spots (Fig. 2A). Gills apicomedial expansion moderately developed (gill 4 expansion rate ca. 0.08); lateral tracheae invisible (Fig. 3A).

Diagnosis. The male adult of $U$. annulata can be distinguished from its congeners by the $\mathrm{Y}$-shaped penes which bear curved apicolateral spines (Fig. 1A). The female adult cannot be distinguished from its congeners. The larva can be distin- 


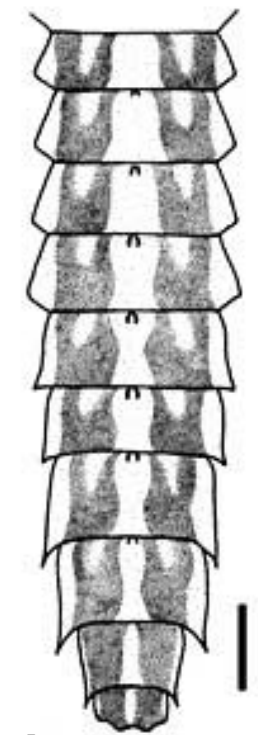

A

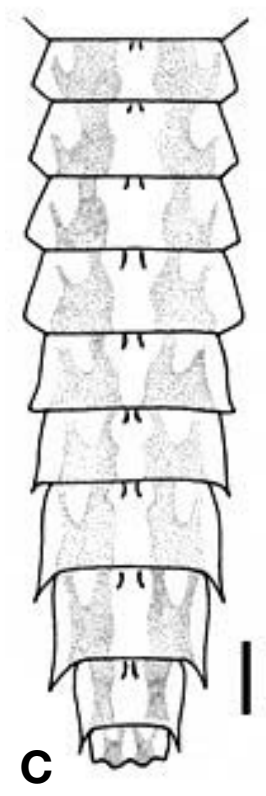

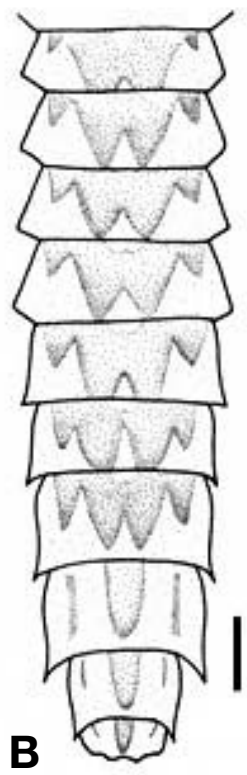

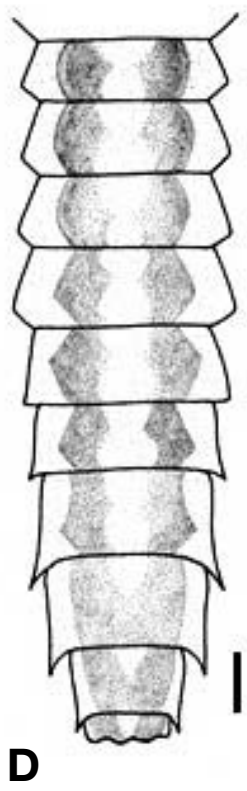

Fig. 2. Larval dorsal abdomen: $A$, Ulmerophlebia annulata; $B$, U. deani; C, U. mjobergi; D, U. pipinna. Scale bars: A-D=0.5 $\mathrm{mm}$.

guished by the gills of which the apicomedial expansion is moderately developed and the lateral tracheae are invisible (Fig. 3A). Larval abdominal terga have broad median light areas and small dark brown submedian spots (Fig. 2A).

Distribution. NSW, VIC.

Remarks. Harker (1950) described the male and female adults of Deleatidium annulatum using specimens from New South Wales. Harker (1954) later described the larva of this species using specimens from another locality in New South Wales, but the description lacked sufficient characters to clearly distinguish this species. Dean (1999) considered this species as Ulmerophlebia, but Bae et al. (2004) did not include this species in Ulmerophlebia because the original descriptions of the adult (e.g., wings) and larva (e.g., maxillary palp) did not fit within the generic definition for Ulmerophlebia. The holotype and paratypes of this species are not located in the Australian Museum in Sydney or British Museum (Natural History) in London (Finlay KJ, unpublished data). Although the original descriptions do not contain complete diagnostic characters for the adult and larva, characters such as the male genitalia with apicolaterally spined penes (see figs. 24 and 24a in Harker, 1950) and the "definite brown annulated" caudal filaments are very similar to our fresh material from New South Wales. We therefore include this species in the genus and redescribe the adult and larva. This species is widely distributed and common in New South Wales and Victoria. The suggested common name of this species is the 'annulate hornless burrowing mayfly.' Dean (1999) also considered Atopopus spadix Harker, 1950 as Ulmerophlebia, but we were unable to recognize this species from our material.

Ulmerophlebia deani Bae \& Finlay, n. sp. (Figs. 2B, 3B) Ulmerophlebia AV3: Dean 1999: 75 (L key).

Type material. Holotype: Mature female larva (EPH-1260: ANVC), Australia, Southeastern Queensland, Stony Creek, Conondale Range, 26 Aug 1997, Dean J [MV]. Paratypes: 1 mature male larva (EPH-1437), Australia, Northern Queensland, Barron River at Goonarra Creek, 6 Nov 1995, Herbert B [MV]; 1 mature female larva (EPH-1089), Australia, Northern Queensland, Birthday Creek at Paluma, 11 Aug 1990, Benson L [MV].

Other material. QLD: 1 L, Birthday Ck nr Paluma, 29 Aug 1997, Cartwright D [MV].

Description. Imago and subimago: Unknown.

Larva (holotype): Female body length $9.0 \mathrm{~mm}$; caudal filaments $9.8 \mathrm{~mm}$ [Male body length $7.0 \mathrm{~mm}$; caudal filaments $5.6 \mathrm{~mm}$ ]. General body colour light yellow with dark purplish brown markings. Head light brown, length $1.56 \mathrm{~mm}$, width $1.90 \mathrm{~mm}$, with dark brown areas at vertex and between lateral ocelli. Female compound eyes width $0.24 \mathrm{~mm}$; distance between compound eyes $1.43 \mathrm{~mm}(\mathrm{~B} / \mathrm{D}=5.96)$ [Male compound eyes width $0.56 \mathrm{~mm}$; distance between compound eyes $0.40 \mathrm{~mm}(\mathrm{~B} / \mathrm{D}=0.71)]$. Antennae length $4.0 \mathrm{~mm}$; 2nd segment dark brown. Clypeus greatly developed, length 0.52 $\mathrm{mm}$, basal width $1.00 \mathrm{~mm}$, apical width $0.84 \mathrm{~mm}$, with well developed sublateral projections, with ca. 8-10 hair-like setae subapicolaterally, with ca. 4-6 hair-like setae subba- 

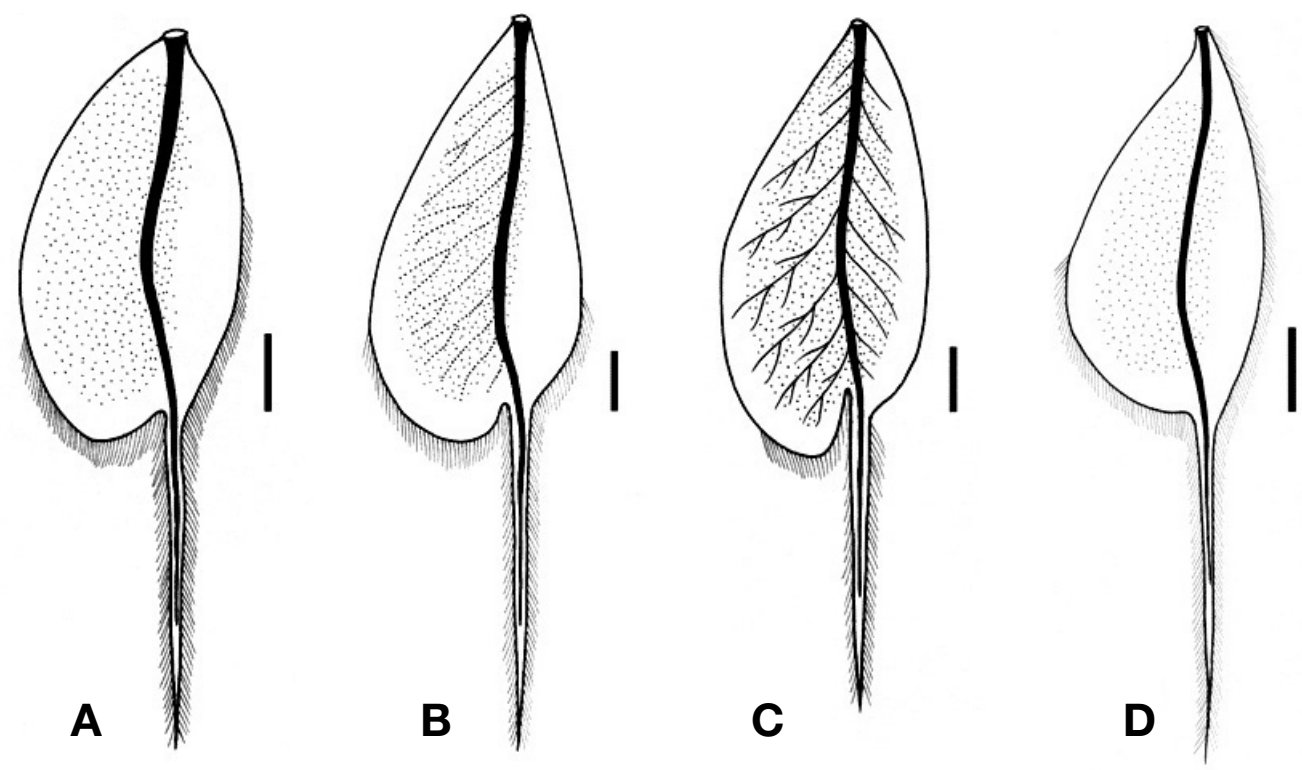

Fig. 3. 4th gill, dorsal lamella: A, Ulmerophlebia annulata; B, U. deani; C, U. mjobergi; $\mathrm{D}$, U. pipinna. Scale bars: $\mathrm{A}-\mathrm{D}=0.25 \mathrm{~mm}$.

solaterally. Labrum slightly narrower than clypeus, distally slightly wider (maximum length $0.24 \mathrm{~mm}$; basal width 0.73 $\mathrm{mm}$; distal maximum width $0.75 \mathrm{~mm}$ ). Maxillary palp segment $10.48 \mathrm{~mm}$, segment $20.32 \mathrm{~mm}$, segment $30.16 \mathrm{~mm}$. Labial palp segment $10.48 \mathrm{~mm}$, segment $20.29 \mathrm{~mm}$, segment $30.24 \mathrm{~mm}$. Pronotum length $0.87 \mathrm{~mm}$, width $1.90 \mathrm{~mm}$, with submedian and sublateral dark brown irregular markings; lateral margins white. Mesonotum with submedian dark brown irregular markings and dots; forewingpads with small black spots basally, laterally and centrally. Sterna with various dark brown markings. Forelegs without distinct markings; forefemora $1.75 \mathrm{~mm}$, foretibiae $1.59 \mathrm{~mm}$, foretarsi $0.63 \mathrm{~mm}$, foreclaws $0.24 \mathrm{~mm}$; forefemora with a few hair-like setae on dorsal and ventral surfaces, with hair-like setal field along posterior margin (anterior margin with few hair-like setae); foretibiae with relatively sparse hair-like setae dorsally and along inner and outer margins, with stout setal field along inner margin 4/5 apically; foretarsi with hair-like setae covering dorsal and lateral surfaces; foreclaws apically dark brown. Midlegs and hindlegs without distinct markings. Abdominal terga with $\mathrm{W}$-shaped broad median dark brown markings, without submedian dark spots, without long hairlike setal field along median line, with hair-like setal row along lateral margins; abdominal segment VI-IX with well developed posterolateral projections (Fig. 2B). Abdominal sterna bare, without markings. Gills apicomedial expansion moderately developed (gill 4 expansion rate ca. 0.10); lateral tracheae ambiguously visible (Fig. 3B). Caudal filaments white.

Diagnosis. The larva of $U$. deani can be distinguished from its congeners by the gills of which the apicomedial expansion is moderately developed and the lateral tracheae are ambiguously visible (Fig. 3B). Larval abdominal terga have W-shaped broad median dark brown markings (Fig. 2B).

Etymology. This species is named after Mr. John Dean who recognized this species for the first time (Dean, 1999).

Distribution. QLD.

Remarks. The suggested common name is the 'W-marked hornless burrowing mayfly.'

Ulmerophlebia minuta Bae \& Campbell, n. sp. (Fig. 1B)

Type material. Holotype: Male imago (EPH-1080), Australia, Northern Queensland, Kuranda, c 360 m, 30 Mar 1976, Quick WNB [MV]. Paratypes: 10 female imagos (EPH1079), same data as Holotype [MV].

Other material. QLD: 25 FI, 1 MS, same locality as holotype, 21, 23 Jan 1975, 30 Mar 1976, 8, 21 Apr 1976, Quick WNB [MV].

Description. Male imago (holotype): Body length $6.9 \mathrm{~mm}$. General body colour light yellow with dark purplish brown markings. Dorsal compound eyes orange in alcohol, length $0.95 \mathrm{~mm}$, width $0.87 \mathrm{~mm}$, height $0.56 \mathrm{~mm}$, broadly meeting posteromedially $(\mathrm{B} / \mathrm{D}=0)$; basal compound eyes black, length $0.64 \mathrm{~mm}$, height $0.29 \mathrm{~mm}$. Thorax colour orange with various dark brown markings; pronotum length $0.24 \mathrm{~mm}$, width $0.71 \mathrm{~mm}$, deeply concave posteromedially, with submedian and sublateral dark brown stripes; pleura and sterna with various irregular dark brown markings and spots including large vertical markings on mesopleura; metanotum dark 
brown. Forewings hyaline, length $6.9 \mathrm{~mm}$, width $2.4 \mathrm{~mm}$; longitudinal veins hyaline; crossveins dark purplish brown; crossveins C-Sc 16, strongly infuscated; crossveins Sc- $\mathrm{R}_{1}$ 12 , infuscated; crossveins $R_{1}-R_{2} 11$; crossveins in stigmatic area not anastomosed (basally located 3 crossveins in stigmatic area closely located each other and forming large dark purplish brown marking). Hindwings hyaline, length $1.3 \mathrm{~mm}$, width $0.8 \mathrm{~mm}$; veins hyaline; crossveins $\mathrm{C}-\mathrm{Sc} 5$, apically concentrated; crossveins $\mathrm{Sc}_{-} \mathrm{R}_{1} 5$; costal area round with indistinct costal projection; Rs $0.40 \mathrm{~mm} ; \mathrm{R}_{1} 0.56 \mathrm{~mm}$; MPs 0.24 $\mathrm{mm} ; \mathrm{MP}_{1} 0.71 \mathrm{~mm}$. Legs light yellow with joints dark brown; dorsal forefemora with purplish brown markings basally, at mid-length and apically; forefemora $1.59 \mathrm{~mm}$, foretibiae 2.22 $\mathrm{mm}$, foretarsal segment $10.10 \mathrm{~mm}$, segment $20.95 \mathrm{~mm}$, segment $30.84 \mathrm{~mm}$, segment $40.32 \mathrm{~mm}$, segment $50.11 \mathrm{~mm}$, foreclaws $0.24 \mathrm{~mm}$. Abdomen colour white with dark brown markings; abdominal segment 1 entirely dark brown (forming unique dark brown ring-marking together with dark brown metanotum); terga with narrow dark brown stripes posteromarginally and anteromedially (forming T-shaped marking), with anterolateral and subanterolateral dark brown spots (anterolateral spots darker). Penes (Fig. 1B) rudimentary, light yellow, with joints light brown, length $0.05 \mathrm{~mm}$, slightly visible from ventral view; forceps light yellow; forceps segment $10.64 \mathrm{~mm}$, segment $20.08 \mathrm{~mm}$, segment $30.06 \mathrm{~mm}$; forceps segment 1 basally broad and apically slender with distinct constriction at 2/3 apically. Caudal filaments length $7.5 \mathrm{~mm}$, light yellow with alternating broad and narrow dark brown markings.

Female imago: Body length $6.3-7.9 \mathrm{~mm}$. General body colour and markings similar to male. Compound eyes width $0.29 \mathrm{~mm}$; distance between compound eyes $1.03 \mathrm{~mm}(\mathrm{~B} / \mathrm{D}=$ 3.60). Forewings length $8.5 \mathrm{~mm}$, width $2.9 \mathrm{~mm}$; venation, veins colour and markings similar to male. Hindwings hyaline, length $1.6 \mathrm{~mm}$, width $0.9 \mathrm{~mm}$; veins hyaline; venation similar to male. Abdomen basally with unique dark brown ring-marking as in male; terga with elongated round dark brown submedian markings and with anterolateral and subanterolateral dark brown dots; terga VII-IX light purplish brown. Caudal filaments $10.6 \mathrm{~mm}$, with alternating broad and narrow dark brown markings.

Larva: Unknown.

Diagnosis. The male adult of $U$. minuta can be easily distinguished from its congeners by the greatly reduced penes (Fig. 1B). Male and female adults have unique dark brown ringmarking on basal abdomen, which may also distinguish them from its congeners.

Etymology. The specific name of this species refers to the 'minute' or rudimentary penes which characterize this species.

Distribution. QLD.
Remarks. The type specimens of this species were labeled as Ulmerophlebia AV5 by Dean J, but this informal assignment has not been used in any previous publications. The suggested common name of this species is the 'minute hornless burrowing mayfly.'

\section{Ulmerophlebia mjobergi (Ulmer) (Figs. 1C, 2C, 3C)}

Euphyurus mjobergi Ulmer 1916: 10 [holotype stage: MI; locality: QLD, Cedar Cr.; deposition: Stockholm Museum]. Deleatidium mjobergi (Ulmer): Ulmer 1920: 115 (MI); Harker 1954: 253 (key).

Ulmerophlebia mjobergi (Ulmer): Demoulin 1955: 228 (generic combination); Campbell 1988: 20 (catalogue); Hubbard \& Campbell 1996: 32 (catalogue).

Ulmerophlebia AV6: Dean 1999: 74 (L key).

Material examined. QLD: 1 MI, 3 FI, Canal Ck, u/s Jct Eliot $\mathrm{Ck}, 142^{\circ} 25^{\prime} \mathrm{E}, 11^{\circ} 23^{\prime} \mathrm{S}$, at UV light, 6 Feb 1992, Cartwright D, Wells A [MV]; 1 L, Eliot Ck, u/s Jct Canal Ck, 7 Feb 1992, Cartwright D, Wells A [MV]; 15 MS, 4 FS, Cape York Peninsula, Upper Jardine R, $142^{\circ} 36^{\prime} \mathrm{E} 11^{\circ} 36^{\prime} \mathrm{S}, 26$ Oct 1979 , Molds MS, Molds BJ [MV]; 11 MS, 3 FS (eggs examined with SEM), $14 \mathrm{~L}$, Cockatoo Ck, Telegraph Crs, $142^{\circ} 27^{\prime} \mathrm{E}$, $11^{\circ} 39^{\prime} \mathrm{S}, 5,6,11$ Feb 1992, Cartwright D, Wells A [MV]; 1 FI, 2 FS, 3 L, Bertie Ck at $250 \mathrm{~m} \& 1 \mathrm{~km}$ SE Healthlands H.S., $142^{\circ} 35^{\prime} \mathrm{E}, 11^{\circ} 45^{\prime} \mathrm{S}, 4,5,11,16$ Feb 1992, Cartwright D, Wells A [MV]; 8 MS, 1 FS (reared, with L exuvium), 17 L (4 L: EPH-1094, ANVC), Bertie Ck, Telegraph Crs, $142^{\circ}$ $30^{\prime} \mathrm{E}, 11^{\circ} 50^{\prime} \mathrm{S}, 5,12$ Feb 1992, Cartwright D, Wells A [MV]; 2 MS, 1 FS, 5 L, McDonnell Ck \& Cockatoo Ck Jct, 8, 13, 18 Feb 1992, Cartwright D, Wells A [MV]; 1 FI, 7 MS, 3 FS, $5 \mathrm{~L}$, Dulhunty R, Telegraph Crs, $142^{\circ} 30^{\prime} \mathrm{E}, 11^{\circ} 50^{\prime} \mathrm{S}, 8,9$, 10 , 15, 18, 19 Feb 1992, Cartwright D, Wells A [MV]; 3 MS, 2 FS, Hann R, 70 mi S of Coen, 23 Jun 1970, LeSouef [MV]; $1 \mathrm{~L}$, Gonshot Ck, Telegraph Crs, 12 Feb 1992, Cartwright D, Wells A [MV]; 1 L, Cholmondeley Ck, Telegraph Crs, 8 Feb 1992, Cartwright D, Wells A [MV].

Redescription. Male imago: Body length $7.0 \mathrm{~mm}$. General body colour light yellow with dark purplish brown markings. Dorsal compound eyes orange in alcohol, length $0.92 \mathrm{~mm}$, width $0.78 \mathrm{~mm}$, height $0.55 \mathrm{~mm}$; distance between dorsal eyes $0.05 \mathrm{~mm}(\mathrm{~B} / \mathrm{D}=0.06)$; basal compound eyes black, length $0.66 \mathrm{~mm}$, height $0.31 \mathrm{~mm}$. Thorax colour light yellow with various dark brown markings; pronotum posteromedially deeply concave, with submedian and lateral dark brown stripes; mesonotum marginally dark brown; pleura and sterna with various irregular dark brown markings and spots including mesopleural vertical markings and transverse sternal stripes; metanotum dark brown. Forewings hyaline, length $6.6 \mathrm{~mm}$, width $2.2 \mathrm{~mm}$; longitudinal veins hyaline (Sc and $\mathrm{R}_{1}$ basally stained light yellowish); crossveins dark purplish 
brown; crossveins C-Sc 12, strongly infuscated; crossveins Sc- $R_{1} 12$, infuscated; crossveins $R_{1}-R_{2} 10$, infuscated; 3 crossveins in basal stigmatic area and near bullae somewhat concentrated and forming large dark purplish brown markings. Hindwings hyaline, length $1.3 \mathrm{~mm}$, width $0.7 \mathrm{~mm}$; veins hyaline; crossveins C-Sc 4-5, apically concentrated; crossveins $\mathrm{Sc}-\mathrm{R}_{1} 5$; costal area round with indistinct costal projection at mid-length; Rs $0.31 \mathrm{~mm}$; $\mathrm{R}_{1} 0.44 \mathrm{~mm}$; MPs $0.31 \mathrm{~mm}$; $\mathrm{MP}_{1}$ $0.47 \mathrm{~mm}$. Legs light yellow; dorsal forefemora with purplish brown markings basally, at mid-length and apically. Abdomen colour white to light yellow with purplish brown markings; terga purplish brown with broad longitudinal median white stripe and anterosublateral and lateral white areas, with anterolateral dark purplish brown spots. Sterna with dark purplish brown longitudinal stripe (margins not clearly demarcated); sterna I posterior 1/2 dark purplish brown. Penes (Fig. 1C) Y-shaped, length $0.14 \mathrm{~mm}$, apically pronounced, with pointed light yellow processes apicolaterally, with apical and dorsolateral light brown areas; forceps light yellow; forceps segment $10.63 \mathrm{~mm}$, segment $20.06 \mathrm{~mm}$, segment 3 $0.06 \mathrm{~mm}$; forceps segment 1 basally broad and apically slender with distinct constriction at 2/3 apically, arched dorsally at constriction. Caudal filaments light yellow with alternating broad and narrow dark brown markings.

Female imago: Body length $6.3-6.5 \mathrm{~mm}$. General body colour and markings similar to male. Compound eyes width $0.27 \mathrm{~mm}$; distance between compound eyes $0.83 \mathrm{~mm}(\mathrm{~B} / \mathrm{D}=$ 3.11). Forewings length $7.3 \mathrm{~mm}$, width $2.5 \mathrm{~mm}$; venation, vein colour and markings similar to male. Hindwings hyaline, length $1.3 \mathrm{~mm}$, width $0.8 \mathrm{~mm}$; veins hyaline; venation similar to male. Abdomen colour and markings similar to male. Caudal filaments with alternating broad and narrow dark brown markings.

Larva: Male body length 7.0-7.2 mm; caudal filaments 5.6 $\mathrm{mm}$. Female body length 7.5-9.3 mm; caudal filaments $6.3-$ $6.9 \mathrm{~mm}$. General body colour light yellow with dark purplish brown markings. Head light brown, length $1.27 \mathrm{~mm}$, width $1.59 \mathrm{~mm}$, with dark brown areas between lateral ocelli, at sublateral vertex and along ecdysal line. Male compound eyes width $0.48 \mathrm{~mm}$; distance between compound eyes 0.52 $\mathrm{mm}(\mathrm{B} / \mathrm{D}=1.10)$. Female compound eyes width $0.24 \mathrm{~mm}$; distance between compound eyes $1.11 \mathrm{~mm}(\mathrm{~B} / \mathrm{D}=4.67)$. Antennae length $4.0 \mathrm{~mm}$; 2nd segment dark brown. Clypeus length $0.40 \mathrm{~mm}$, basal width $0.68 \mathrm{~mm}$, apical width $0.64 \mathrm{~mm}$, with well developed sublateral projections, with ca. 8-10 hair-like setae subapicolaterally, with ca. 4-6 hair-like setae subbasolaterelly. Maxillary palp segment $10.26 \mathrm{~mm}$, segment $20.29 \mathrm{~mm}$, segment $30.12 \mathrm{~mm}$. Labial palp segment 1 $0.38 \mathrm{~mm}$, segment $20.27 \mathrm{~mm}$, segment $30.20 \mathrm{~mm}$. Pronotum length $0.80 \mathrm{~mm}$, width $1.59 \mathrm{~mm}, 1 / 2 \times$ longer than wide, with submedian and sublateral dark brown irregular markings; anterolateral margin round; lateral margin white with row of sparse hair-like setae. Mesonotum with submedian dark brown irregular markings and dots; forewingpads with small black spots basally and centrally. Thoracic sterna with various dark brown markings. Forefemora $1.32 \mathrm{~mm}$, foretibiae $1.32 \mathrm{~mm}$, foretarsi $0.56 \mathrm{~mm}$, foreclaws $0.24 \mathrm{~mm}$; forefemora with dark brown stripes dorsally and ventrally at basal, midlength and apical areas. Abdominal terga (Fig. 2C) with broad submedian dark brown stripes and with light areas along median line, lateral margins and anterosublateral areas (median light area somewhat $\mathrm{Y}$-shaped containing paired small dark dots anterosubmedially); abdominal segment VI-IX with well developed posterolateral projections. Abdominal sterna with dark brown stripe along median line. Gills apicomedial expansion strongly developed (gill 4 expansion rate ca. 0.19); lateral tracheae dark brown and distinct; margins with dense fine setae only in apical area of expansion (Fig. 3C). Caudal filaments light yellow, with alternating broad and narrow dark brown markings.

Diagnosis. The male adult of $U$. mjobergi can be distinguished from its congeners by the Y-shaped penes, which bear apicolateral processes (Fig. 1C). The larva can be distinguished by the gills of which the apicomedial expansion is strongly developed and the lateral tracheae are distinctly visible (Fig. 3C). Larval abdominal terga (Fig. 2C) have broad median light area and anterosublateral light areas, containing submedian dark spots.

Distribution. QLD.

Remarks. Although we were unable to locate the holotype material of this species in the Stockholm Museum, the adult and larval material from Queensland could readily be identified based on the original description of Ulmer (1916). The suggested common name of this species is the 'common hornless burrowing mayfly.'

Ulmerophlebia pipinna Suter (Figs. 1D, 2D, 3D)

Ulmerophlebia pipinna Suter 1986: 352 [MI]; Campbell 1988:

20 (catalogue); Hubbard \& Campbell 1996: 32 (catalogue). Ulmerophlebia AV1: Dean 1999: 74 (L key).

Type material. Holotype: Male imago (wings and legs on slides, T-8953), Australia, Victoria, Grampian Mountains, Second Wannon River(GR. 547396), 25 Sep 1977, Suter PJ, Suter DN [MV]. Paratypes: 2 male imagos (T-8954), same data as holotype [MV]; 1 larva (T-8955), Australia, SE South Australia, Hitchcocks Drain, 22 Sep 1977, Suter PJ, Suter DN [MV].

Other material. VIC: $5 \mathrm{MI}, 1 \mathrm{FI}, 1 \mathrm{MS}$, Yea R at $7 \mathrm{~km} \mathrm{~S}$ of Glenburn, 1 Dec 1972, Neboiss A [MV]; 2 FI, Tarago R at 7 km W of Neerim, 1 Mar 1972, Neboiss A [MV]; 1 MI, Hopkins R at Hopkins Falls, 6 Mar 1978, Calder AA [MV]; 1 FI, 
Maramingo Ck at $5 \mathrm{~km}$ NE of Genoa, 29 Mar 1974, Neboiss A [MV]; 1 MI, Erinunderra R at $15 \mathrm{~km} \mathrm{~N}$ of Club Terrace, 11 Nov 1975, Blyth J [MV]; 1 FI, Yarra R below Upper Yarra Dam, 28 Feb 1976, Neboiss A [MV]; 5 L, Yarra R at Hazlewood Rd, 17 Feb 1978, Dean J [MV]; 1 MI (reared, with L exuvium), Yarra R at Hazlewood Rd, 23 Feb 1984 [MV]; 3 MI, Starvation Ck, 20 Feb 1976, Dean J [MV]; 1 MI (reared, with L exuvium), 1 FI (reared, with L exuvium), Starvation Ck, 19 Mar 1976, Dean J [MV]; 1 MI, Healesville, Coranderrk Reserve, 26 Mar 1976, Aankin [MV]; 4 FI, Delegate R at $8 \mathrm{~km} \mathrm{SW}$ of Bendock, 15 Dec 1976, Neboiss A [MV]; 1 MI, 1 FI, Diamond Ck at 7 km SE of Gembrook, 31 Jan 1979, Wells A, Neboiss A [MV]; 1 FI, Gellibrand R at Asplin Ck Jct, 28 Jan 1982, Neboiss A [MV]; 2 MI (reared, with L exuvium), Watts R at Fernshaw, 4 Mar 1976, Dean J [MV]; 2 FI (reared, with L exuvium), Badger $\mathrm{Ck} \mathrm{d} / \mathrm{s}$ weir, 18 Jan 1980; 1 FI (reared, with L exuvium), Armstrong Ck, 16 Dec 1983, Dean J [MV]; 2 L (EPH-0957: ANVC), Mt Buffalo, Crystal Brook, 7 Jun 1977, Dean J [MV]; 1 MI, 1 MS, Tanjil R Jct, $10 \mathrm{~km}$ N of Willow Grove, 18 Dec 1973, Neboiss A [MV]; 2 L (EPH-0971: VVC), LaTrobe R (Survey St. 17), Tanjil R, 19 Feb 1973 [MV]; 1 MI (reared, with L exuvium), LaTrobe $\mathrm{R}$ at $\mathrm{Br}$ of $\mathrm{SW}$ Willow Grove, $10 \mathrm{Dec}$ 2000, Bae YJ, Campbell I [MU]; 1 L, Grampians, Stony Ck, 26 Nov 1990, Cartwright D [MV]; 2 L, Wannon R at Serra Rd, 4 Dec 1983, Dean J, Cartwright D [MV]; 2 L, Snobs Ck Falls, $145^{\circ} 53^{\prime} \mathrm{E}, 37^{\circ} 18^{\prime} \mathrm{S}, 27$ Dec 1982, Neboiss A [MV]; 2 L, Glenelg R, Big cord, 7 Mar 1995 [MV].

Redescription. Male imago: Body length $8.5-8.7 \mathrm{~mm}$. General body colour light yellowish brown with dark purplish brown markings. Dorsal compound eyes orange in alcohol, length $0.98 \mathrm{~mm}$, width $0.78 \mathrm{~mm}$, height $0.42 \mathrm{~mm}$, completely connected at posterior part $(\mathrm{B} / \mathrm{D}=0)$; basal compound eyes black, length $0.52 \mathrm{~mm}$, height $0.36 \mathrm{~mm}$. Thorax colour light yellowish brown with various dark purplish brown markings; pronotum dark purplish brown, posteromedially deeply concave; mesonotum posterolaterally purplish brown; metanotum dark purplish brown; pleura light yellowish brown to purplish brown; sterna purplish brown. Forewings hyaline, length $8.7 \mathrm{~mm}$, width $3.0 \mathrm{~mm}$; veins stained light yellowish brown; crossveins C-Sc, Sc- $\mathrm{R}_{1}$ and $\mathrm{R}_{1}-\mathrm{R}_{2}$ dark purplish brown (basally darker in colour); crossveins C-Sc 18, basal 1/2 infuscated; crossveins $\mathrm{Sc}-\mathrm{R}_{1} 16$, basal $1 / 2$ slightly infuscated; crossveins $R_{1}-R_{2} 13$, slightly infuscated. Hindwings hyaline, length $1.9 \mathrm{~mm}$, width $1.0 \mathrm{~mm}$; veins hyaline; crossveins $\mathrm{C}$ Sc 10, apical 7 crossveins concentrated, stained slightly yellowish brown; crossveins Sc- $\mathrm{R}_{1} 5$, stained slightly yellowish brown; costal area rounded with indistinct costal projection $1 / 3$ basally; Rs $0.27 \mathrm{~mm}$; $\mathrm{R}_{1} 0.75 \mathrm{~mm}$; MPs $0.28 \mathrm{~mm}$; $\mathrm{MP}_{1}$ $1.03 \mathrm{~mm}$. Forelegs yellowish brown; dorsal forefemora with purplish brown markings at mid-length and apically; apical tibiae, tarsal segment 1 and 5, terminal tarsal segments 2, 3 and 4 and claws purplish brown. Forefemora $1.67 \mathrm{~mm}$, foretibiae $2.83 \mathrm{~mm}$, foretalsal segment $10.13 \mathrm{~mm}$, segment 2 $0.97 \mathrm{~mm}$, segment $30.93 \mathrm{~mm}$, segment $40.70 \mathrm{~mm}$, segment $50.30 \mathrm{~mm}$, foreclaws $0.13 \mathrm{~mm}$. Abdomen colour light yellowish brown with dark purplish brown markings; terga purplish brown with broad longitudinal median light yellow stripe, with broad C-shaped dark purplish brown markings, with indistinct anterolateral dark purplish brown spots. Sterna with indistinct dark purplish brown longitudinal stripe (margins not clearly demarcated). Penes (Fig. 1D) V-shaped, slender, dorsoventrally flattened, length $0.16 \mathrm{~mm}$, light purplish brown laterally; forceps light yellow; forceps segment 10.68 $\mathrm{mm}$, segment $20.08 \mathrm{~mm}$, segment $30.08 \mathrm{~mm}$; forceps segment 1 broad basally and slender apically with distinct constriction at mid-length, arched dorsally at constriction; segments 2 and 3 not clearly demarcated. Cerci $9.5 \mathrm{~mm}$, light purplish brown basally, light yellow apically, with alternating dark and light joints.

Female imago: Body length $8.6 \mathrm{~mm}$. General body colour and markings similar to male. Compound eyes width 0.22 $\mathrm{mm}$; distance between compound eyes $1.08 \mathrm{~mm}(\mathrm{~B} / \mathrm{D}=4.91)$. Forewings length $9.4 \mathrm{~mm}$, width $3.2 \mathrm{~mm}$; venation, vein colour and markings similar to male; Hindwings hyaline, length $1.8 \mathrm{~mm}$, width $0.9 \mathrm{~mm}$; veins hyaline; venation similar to male. Abdomen with distinct $\mathrm{C}$-shaped markings similar to male. Caudal filaments light yellow with alternating dark and light joints.

Larva: Male body length 9.2-9.8 mm; caudal filaments 7.6$10.0 \mathrm{~mm}$. Female body length $9.5-11.2 \mathrm{~mm}$; caudal filaments $9.2-13.2 \mathrm{~mm}$. General body colour light yellow to light purplish brown with dark purplish brown markings. Head light purplish brown, length $1.40 \mathrm{~mm}$, width $1.75 \mathrm{~mm}$; clypeus dark purplish brown. Male compound eyes width $0.58 \mathrm{~mm}$; distance between compound eyes $0.43 \mathrm{~mm}(\mathrm{~B} / \mathrm{D}=0.74)$. $\mathrm{Fe}$ male compound eyes width $0.23 \mathrm{~mm}$; distance between compound eyes $1.35 \mathrm{~mm}(\mathrm{~B} / \mathrm{D}=6.00)$. Antennae length $4.0 \mathrm{~mm}$; segments 1 and 2 light purplish brown. Clypeus length 0.45 $\mathrm{mm}$, basal width $0.90 \mathrm{~mm}$, apical width $0.83 \mathrm{~mm}$, with well developed sublateral projections, with ca. 10 hair-like setae subapicolaterally, with ca. 15 hair-like setae subbasolaterelly. Pronotum length $0.83 \mathrm{~mm}$, width $1.86 \mathrm{~mm}$, with submedian and sublateral dark brown irregular markings; lateral margin white with row of sparse hair-like setae. Mesonotum with submedian dark brown irregular markings and dots. Forefemora $1.50 \mathrm{~mm}$, foretibiae $1.38 \mathrm{~mm}$, foretarsi $0.55 \mathrm{~mm}$, foreclaws $0.25 \mathrm{~mm}$. Abdominal terga (Fig. 2D) light yellow with broad median light area, with broad C-shaped dark purplish brown submedian markings, without submedian dark spots; abdominal segment VI-IX with moderately developed posterolateral projections. Abdominal sterna with dark purplish 
brown submedian stripes along median line containing submedian dark spots near anterior margin. Gills (Fig. 3D) apicomedial expansion not developed (gill 4 expansion rate 0 ), lateral tracheae invisible; margins with dense fine setae entirely on outer margin and on apical 1/2 of inner margin. Caudal filaments light yellow.

Diagnosis. The male adult of $U$. pipinna can be distinguished from its congeners by the V-shaped, slender, dorsoventrally flattened penes (Fig. 1D). The larva can be distinguished by the gills of which the apicomedial expansion is not developed and the lateral tracheae are invisible (Fig. 3D). Larval abdominal terga have broad median light area with broad Cshaped dark purplish brown submedian markings (Fig. 2D). Distribution. VIC, SA.

Remarks. The suggested common name of this species is the 'southern hornless burrowing mayfly.'

\section{Key to known species of Ulmerophlebia}

\section{Male imago}

1. Male penes greatly reduced, $<1 / 5 \times$ length from base to constriction of basal segment of forceps (Fig. 1B); QLD …

U. minuta

- Male penes Y-shaped or V-shaped, 1/3-1/2 $\times$ length from base to constriction of basal segment of forceps ….... 2

2. Male penes V-shaped, without apicolateral processes or spines (Fig. 1D); VIC, SA …................... U. pipinna

- Male penes Y-shaped, with apicolateral processes or spines

3. Male penes with apicolateral processes (Fig. 1C); QLD … ........................................ U. mjobergi

- Male penes with apicolateral spines (Fig. 1A); NSW, VIC U. annulata

\section{Larva}

1. Gills apicomedial expansion not developed (gill 4 expansion rate 0 ), lateral tracheae invisible (Fig. 3D); abdominal terga with broad median light area, with broad C-shaped dark purplish brown submedian markings, without submedian dark spots (Fig. 2D); VIC, SA …..... U. pipinna

- Gills apicomedial expansion moderately to strongly developed, lateral tracheae visible or invisible (Fig. 3AC); abdominal terga colour pattern variable $\ldots \ldots \ldots \ldots \ldots 2$

2. Gills apicomedial expansion strongly developed (gill 4 expansion rate ca. 0.19), lateral tracheae distinctly visible (Fig. 3C); abdominal terga with broad median light area and anterosublateral light areas with submedian dark spots (Fig. 2C); QLD …..................... U. mjobergi

- Gills apicomedial expansion moderately developed (gill 4 expansion rate ca. $0.08-0.10$ ), lateral tracheae visible or invisible (Fig. 3A, B); abdominal terga colour pattern various
3. Gills lateral tracheae invisible (Fig. 3A); abdominal terga with broad median light area and anterosublateral light areas with submedian dark spots (Fig. 2A); NSW, VIC ...

U. annulata

- Gills lateral tracheae ambiguously visible (Fig. 3B); abdominal terga with $\mathrm{W}$-shaped broad median dark area (Fig. 2B); QLD …................................ Ueani

\section{ACKNOWLEDGMENTS}

We thank John Dean (Victoria EPA), Richard Marchant (Museum of Victoria), Phil Suter (LaTrobe University), Nigel Ainsworth (Victoria NRE), Fred Govedich (Monash University), Bonnie Bain (Monash University) and Dennis O'Dowd (Monash University) for their loan of material, provision of literature, assistance in the field and useful comments. R. Marchant and K.A. Johanson (Swedish Museum of Natural History, Stockholm) provided useful information on type material of Ulmerophlebia species. This work was conducted during YJB's sabbatical leave (2000-2001) at Monash University, which was supported by the Korea Research Foundation (currently National Research Foundation of Korea).

\section{REFERENCES}

Bae YJ, Finlay KJ, Campbell IC, 2004. Taxonomic status of the Australian mayfly genera Jappa and Ulmerophlebia (Ephemeroptera: Leptophlebiidae). Entomological News, 115:1-10.

Bae YJ, McCafferty WP, 1991. Phylogenetic systematics of the Potamanthidae (Ephemeroptera). Transactions of the American Entomological Society, 117:1-143.

Campbell IC, 1988. Ephemeroptera. In: Zoological catalogue of Australia, Vol. 6 (Ed., Houston WWK). Bureau of Flora and Fauna, Australian Government Publishing Service, Canberra, ACT, pp. 1-22.

Campbell IC, 1990. The Australian mayfly fauna: composition, distribution and convergance. In: Mayflies and stoneflies (Ed., Campbell IC). Kluwer Academic Publications, Dordrecht, pp. 149-153.

Christidis F, 2005. Phylogenetic relationships of the Australian Leptophlebiidae (Ephemeroptera). Invertebrate Systematics, 19:531-539.

Dean JC, 1999. Preliminary keys for the identification of Australia mayfly nymphs of the family Leptophlebiidae. Identification Guide, No. 20. Cooperative Research Center for Freshwater Ecology, Albury, NSW, pp. 1-91.

Dean JC, Suter PJ, 1996. Mayfly nymphs of Australia: a guide to genera. Identification Guide No. 7. Cooperative Research Center for Freshwater Ecology, Albury, NSW, pp. 1-82. 
Demoulin G, 1955. Note sur deux nouveaux genres de Leptophlebiidae d'Australie (Ephemeroptera). Bulletin et Annales de la Société Royale Entomologique de Belgique, 91:227229.

Finlay KJ, Bae YJ, 2008. Phylogenetic relationships of the Australian Leptophlebiidae. In: International advances in the ecology, zoogeography and systematics of mayflies and stoneflies (Eds., Hauer FR, Stanford JA, Newell RL). University of California Press, Berkeley, CA, pp. 233-275.

Harker JE, 1950. Australian Ephemeroptera. Part I. Taxonomy of New South Wales species and evaluation of taxonomic characters. Proceedings of the Linnean Society of New South Wales, 71:1-34.

Harker JE, 1954. The Ephemeroptera of Eastern Australia. Transactions of the Royal Entomological Society of London, 105: 241-268.

Hubbard MD, Campbell IC, 1996. Catalogue of the Australian mayflies, recent and fossil (Insecta: Ephemeroptera). Australian Society for Limnology, Special Publication, 11:1-43.
Peters WL, Campbell IC, 1991. Ephemeroptera (mayflies). In: The insects of Australia. Vol. 1. 2nd ed (Ed., CSIRO). Melbourne University Press, Carlton, VIC, pp. 279-293.

Riek EF, 1970. Ephemeroptera (mayflies). In: The insects of Australia (Ed., CSIRO). Melbourne University Press, Carlton, VIC, pp. 224-240.

Suter PJ, 1986. The Ephemeroptera (mayflies) of South Australia. Records of the South Australian Museum, 19:339-397.

Ulmer G, 1916. Results of Dr. E. Mjöberg's Swedish Scientific Expedition to Australia 1910-1913. 6. Ephemeroptera. Arkiv för Zoologi, 10:1-18.

Ulmer G, 1920. Chilenische Ephemeroptera, hauptsachlich aus dem Deutschen Entomologischen Institut, Berlin-Dahlem. Arbeiten über Morphlogische und Taxonomische Entomologie aus Berlin-Dahlem, 5:85-108.

Received August 12, 2012 Revised September 11, 2012 Accepted September 15, 2012 